\title{
Proceeding
}

7th INSHS International Christmas Sport Scientific Conference, 9-12 December 2012. International Network of Sport and Health

Science. Szombathely, Hungary

\section{Tactics-based water polo training}

\author{
SALVATORE NAPOLITANO, DANIELA TURSI, PIO ALFREDO DI TORE, GAETANO RAIOLA \\ Department of Human, Philosophical and Education Sciences (DISUFF) University of Salerno, Italy
}

\begin{abstract}
Napolitano S, Tursi D, Di Tore PA, Raiola G. Tactis-based water polo training. J. Hum. Sport Exerc. Vol.8, No. Proc2, pp. S271-S282, 2013. Notational analysis quantifies the technical and tactical playing aspects of a game through game-related statistics based mainly on frequencies and effectiveness percentages (Lozovina et al., 2004). Several studies applied the notational analysis technique to water polo (Argudo et al., 2007; Hughes et al., 2006). This work concerns the assessment of tactical aspects in high performance water polo trough performance analysis. The analysis was conducted on 9 matches of the Italian Serie A1 Women's Water Polo played by Volturno. Tactical patterns suggested by the coach were compared with tactical patterns implemented during the game and to actions outcome, in order to acquire elements useful to create a codified tactic system. The results showed a positive correlation between the compliance of tactical patterns implemented during playing with patterns designed by the coach and the final outcome of the action. The data recruitment has been entrusted to the performance analysis, conducted by a team of performance analysts, coaches and statisticians. The video analysis of matches was conducted using the Dartfish TeamPro software. The measurement involved the following technical and tactical parameters: frequency of occurrence of actions, time duration, average number of players involved and passes, frequency of occurrence of turnovers, and frequency of occurrence of number, result, position and type of conclusions. The assessment of compliance for the tactical patterns has prescribed by the coach with the tactical patterns implemented in training session, based on previously determined parameters. The performance analysis was performed to evaluate parameters as frequency of occurrence of actions, time duration, number, result, position and type of shots in relation to tactical patterns, and an evaluation table was constructed by combining the Boolean evaluation of the coach on the compliance of patterns with the action final outcome. The results show a positive and statistically significant correlation coefficient between tactical compliance and action outcome. The result showed a significant correlation between the tactical patterns compliance and offensive effectiveness. This correlation confirmed the need of developing a common methodology for teaching and training water polo through tactics. Key words: WATER POLO, PERFORMANCE ANALYSIS, TACTICAL PATTERNS.
\end{abstract}

Corresponding author. Gaetano Raiola, Via Berenice 11, Napoli, Italy.

Email: raiolagaetano@libero.it

7th INSHS International Christmas Sport Scientific Conference, 9-12 December 2012. International Network of Sport and Health Science. Szombathely, Hungary.

JOURNAL OF HUMAN SPORT \& EXERCISE ISSN 1988-5202

(c) Faculty of Education. University of Alicante

doi:10.4100/jhse.2012.8.Proc2.29

VOLUME 8 | Proc2 | 2013 | S271 


\section{INTRODUCTION}

This pilot work represents an attempt to develop methods and consequential tools to analyze, and then train, tactical water polo side, knowing that

- "The coaches of team sports analyze matches and performances of team and opposing teams to get useful data in coaching" (Hughes \& Franks, 2008) and that.

- "Currently, the process of training, its organization, and teaching methodology need more knowledge on the qualitative aspects of sports performance (Schmidt \& Wrisberg, 2008)".

Nine women water polo matches, during season 2011/2012 (Italian Serie A1), have been analyzed by a water polo coach, helped by a statistician and a performance analyst.

Purpose of the analysis process was:

- to identify single events during the matches,

- to examine the tactical patterns implemented in these events,

- to obtain by the coach an evaluation on tactical pattern compliance and then

- to put this compliance in relation to event's outcome.

Aim of the work is to verify the efficacy of different attack patterns, when they were well-performed, in order to create a codified methodology for teaching water polo through tactics.

The data, collected via Dartfish Team Pro Software, were analyzed trough a "Water polo Tactics Analyzer" software, developed as a web-based application at University of Salerno and released under GPL license, which returned basic descriptive statistics and the correlation coefficient of each pattern with events outcomes.

The results show a positive and statistically significant correlation coefficient between tactical compliance and events outcome, and highlight the need for developing a common methodology for teaching water polo through tactics, confirming once again that "the practical value of performance analysis is that well-chosen performance indicators highlight good and bad techniques or team performances (Hughes)".

\section{METHODS}

The research approach is integrated and consists of 3 distinct methods:

- case study (9 matches of the Italian Serie A1 Women's Championship, season 2011/2012, played by the Volturno s.c.) for the analysis of matches,

- action research method for coach contribution,

- and theoretical-argumentative method to deduce a theoretical framework in which define the data processing.

The survey of data is entrusted to performance analysis, carried out with the help of a water polo coach, a statistician and a performance analyst.

The tool used for measuring is the Dartfish TeamPro software. 
The assessment of compliance for the tactical patterns is entrusted to the coach, on the basis of the video analysis-aided confrontation of attack pattern design against attack pattern effectively implemented during match.

The assessment of compliance for the tactical patterns is entrusted to the coach, on the basis of the video analysis-aided confrontation of attack pattern design against attack pattern effectively implemented during match.

The research team examined matches with Dartfish TeamPro, isolating single keyframes relative to attack events, identifying the implemented attack pattern, then the coach expressed an evaluation on attack pattern compliance.

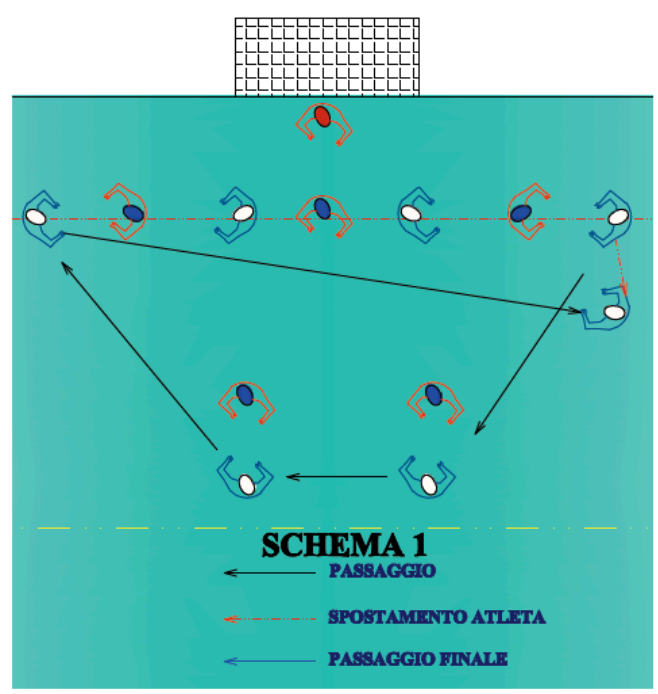

Figure 1. Confrontation between pattern design and effectively implemented pattern during match for attack pattern named "schema1", schema1.

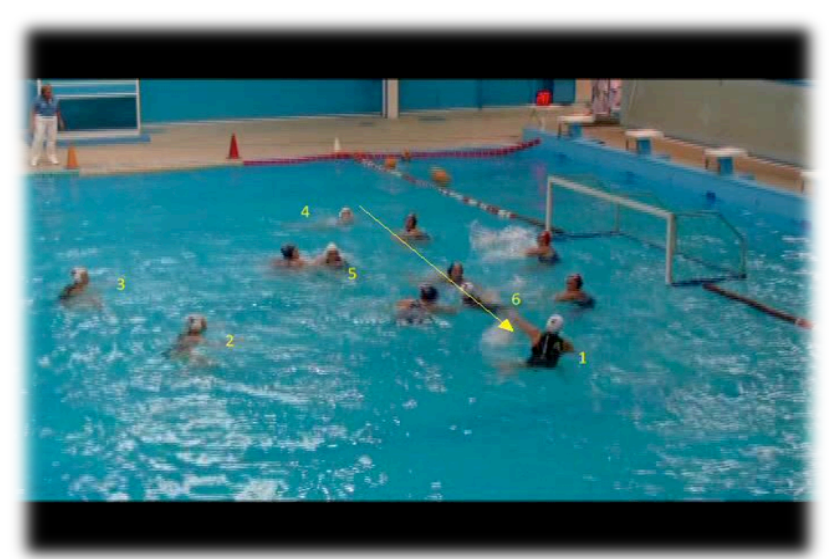

Figure 2. Confrontation between pattern design and effectively implemented pattern during match for attack pattern named "schema1", game snapshot. 
A spreadsheet containing, for each row, the match id, the event id, the attack pattern id, the coach's evaluation (compliant/non compliant) and the event outcome (goal / non goal) was filled. This data sheet is processed through the "water polo Tactics analyzer software", which produces basic descriptive statistics and the correlation coefficient of each well-implemented attack pattern with events outcomes.

In total, 7 attack patterns on 73 events during 9 matches were analyzed. The analyzer software output is discussed by the research team, with consciousness of internal validity, allowed by action research method, of this kind of qualitative analysis.

\section{RESULTS}

An evaluation table was constructed by combining, for each single event, the Boolean evaluation of the coach on the compliance of patterns with the event final outcome.

Here are reported:

- Confrontations of pattern design with Dartfish screenshot of pattern implemented during game;

- Basic descriptive statistics (occurrence of single patterns on events total, occurrence of "wellperformed pattern" on events total, etc...);

- Linear regression scatter plot for single patterns;

- Confrontation between correlation coefficients of single patterns (referred only to "well-performed" patterns).

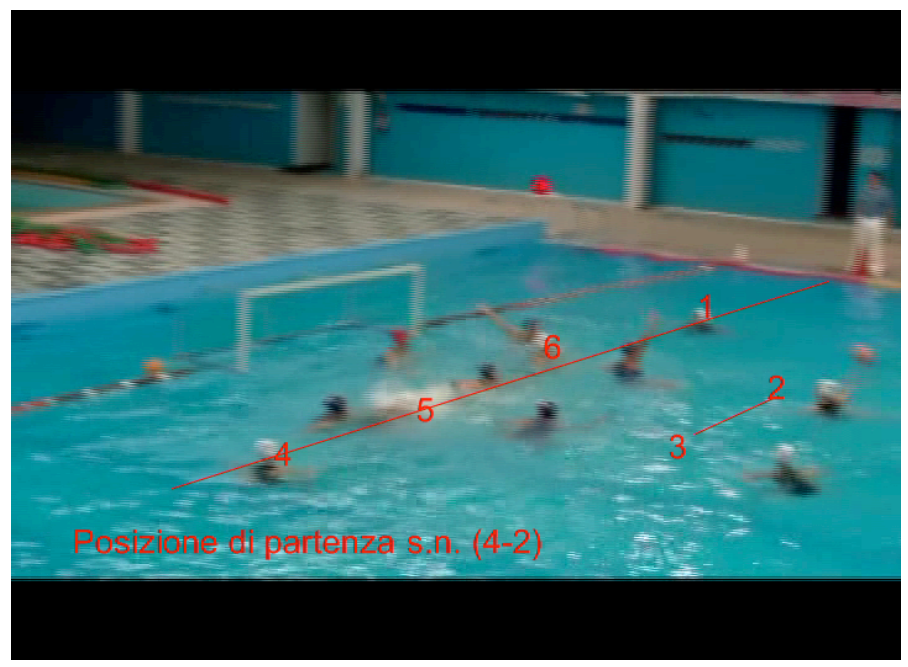

Figure 3. Starting grid. 


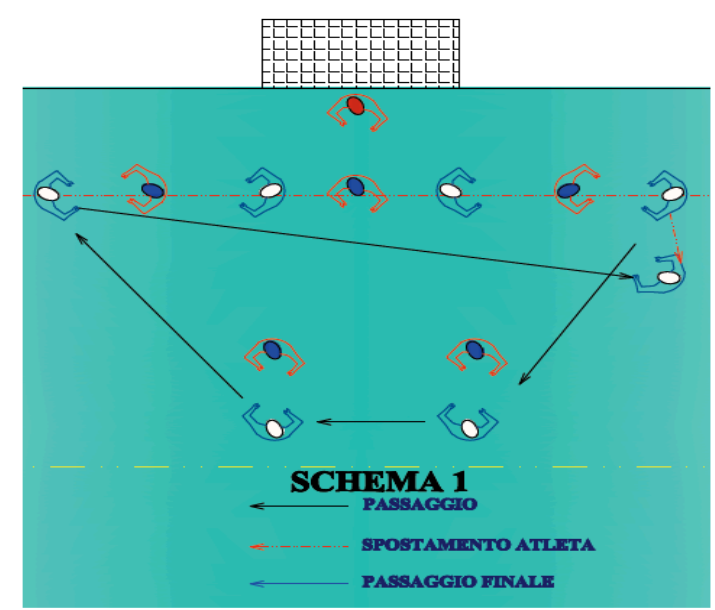

Figure 4. Design of pattern named «schema1».

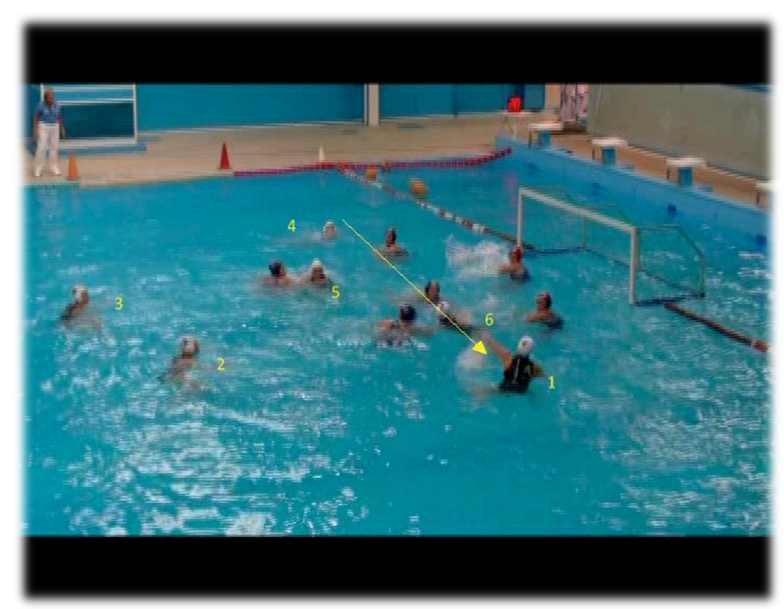

Figure 5. Pattern «schema1» Screenshot.

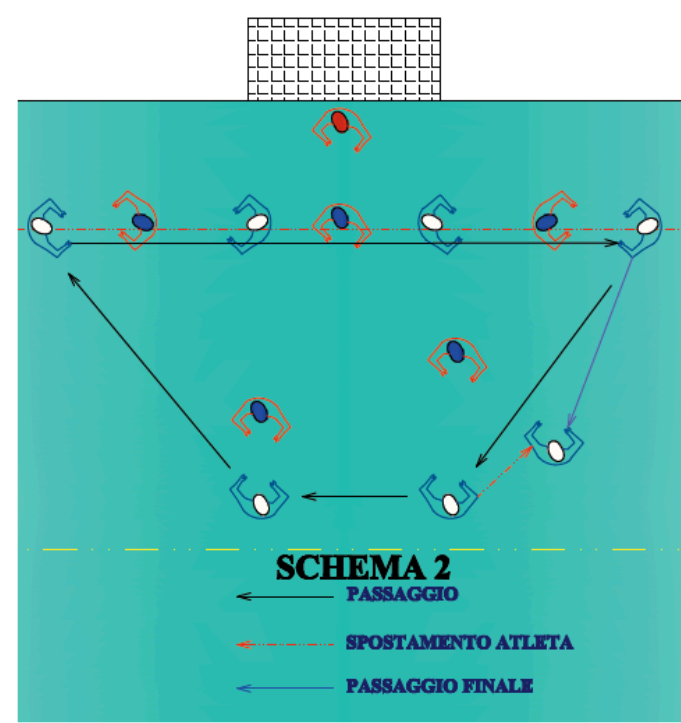

Figure 6. Design of pattern named «schema2». 


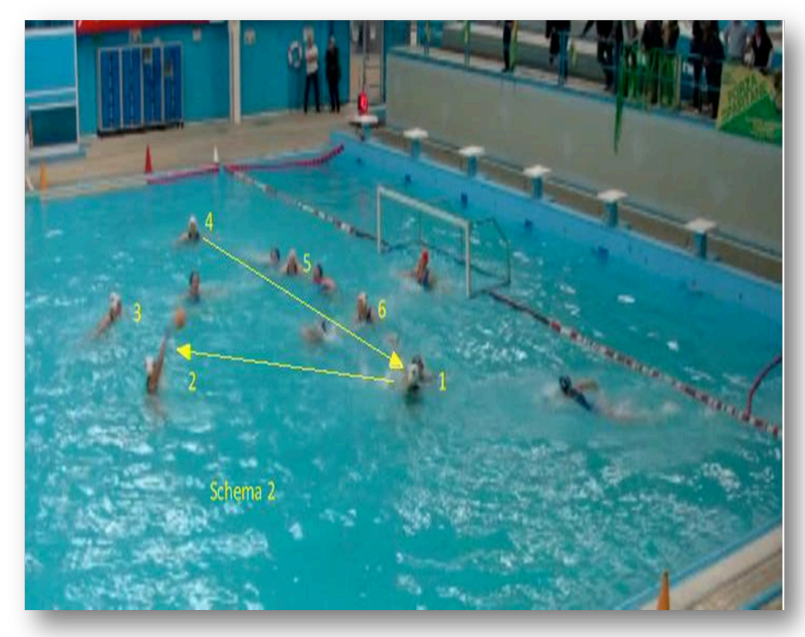

Figure 7. Pattern «schema2» Screenshot.

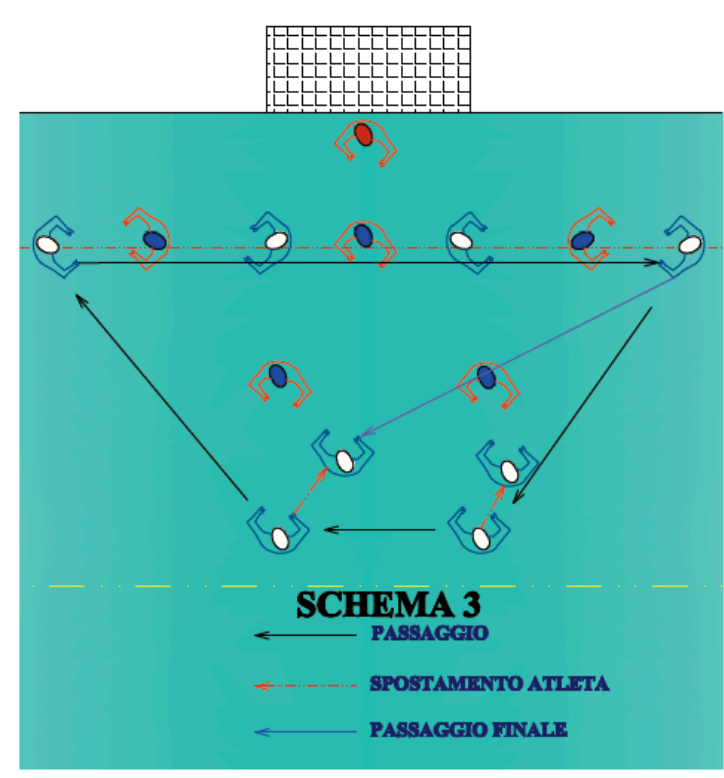

Figure 8. Design of pattern named «schema3».

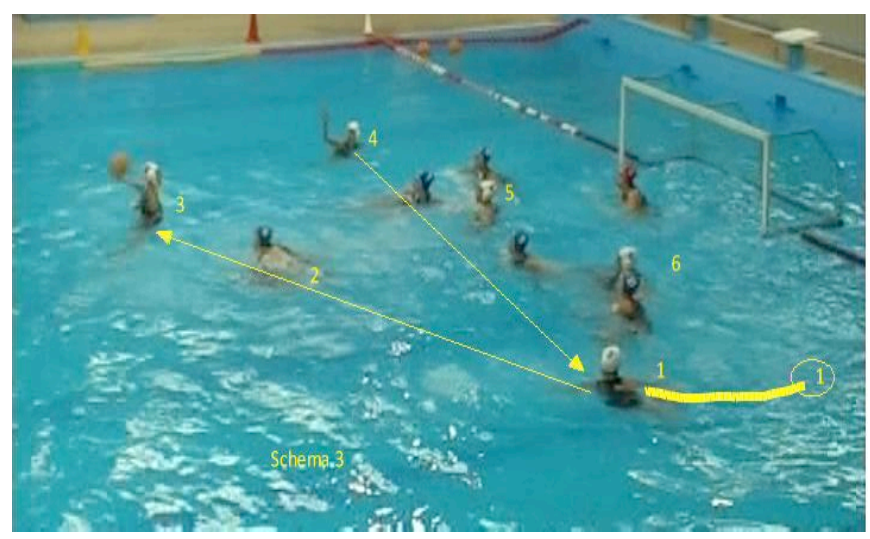

Figure 9. Pattern «schema3» Screenshot. 


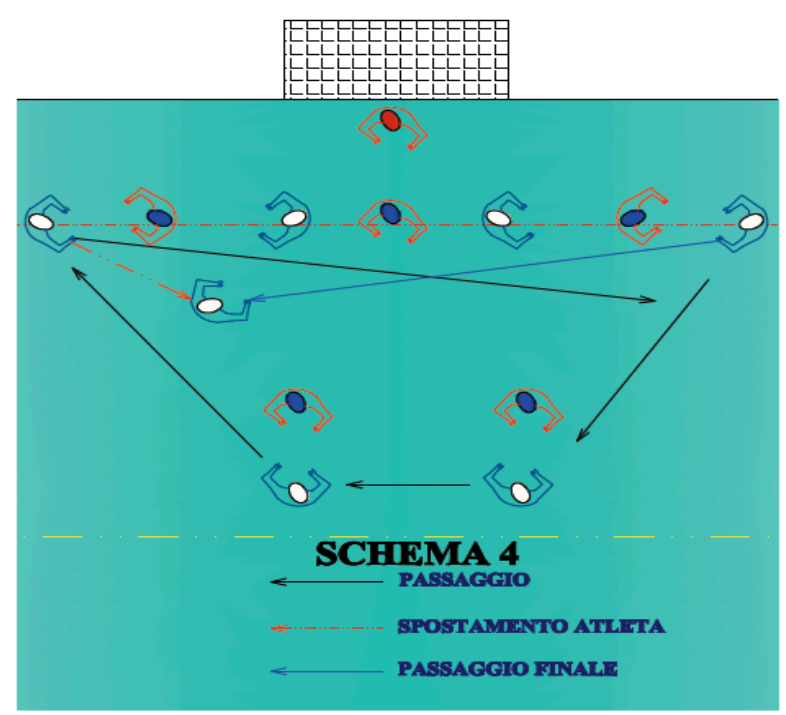

Figure 10. Design of pattern named «schema4».

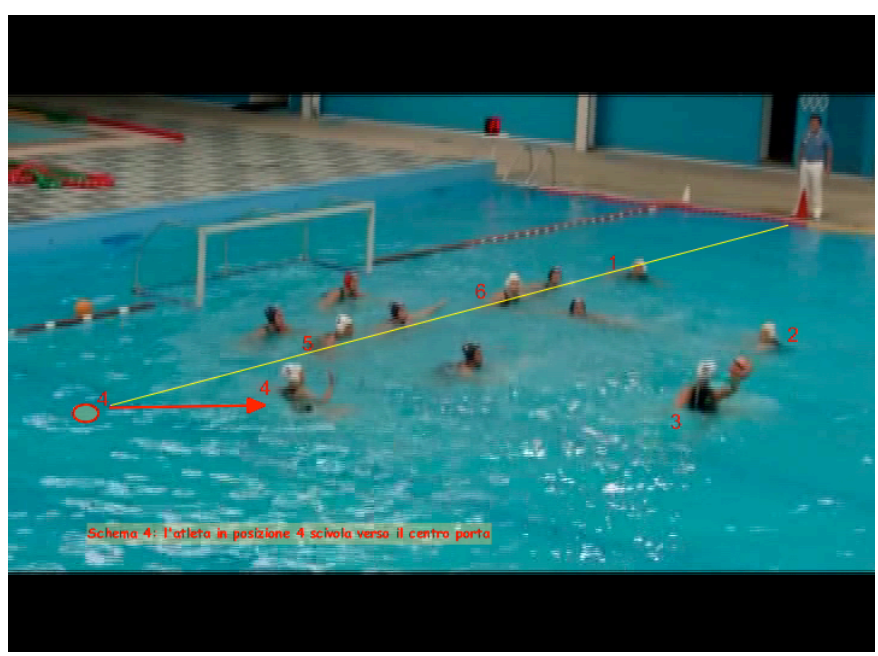

Figure 11. Pattern «Schema4» Screenshot.

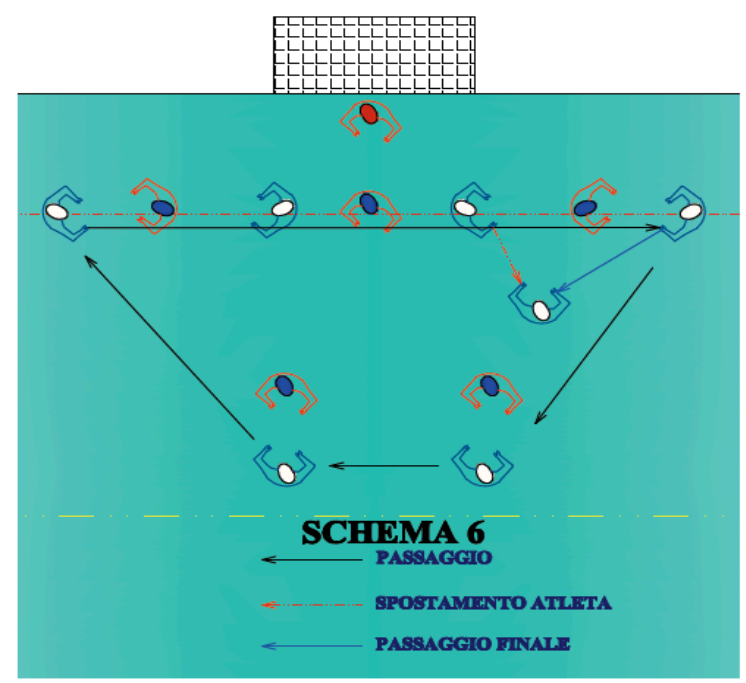

Figure 12. Design of pattern named «schema6». 


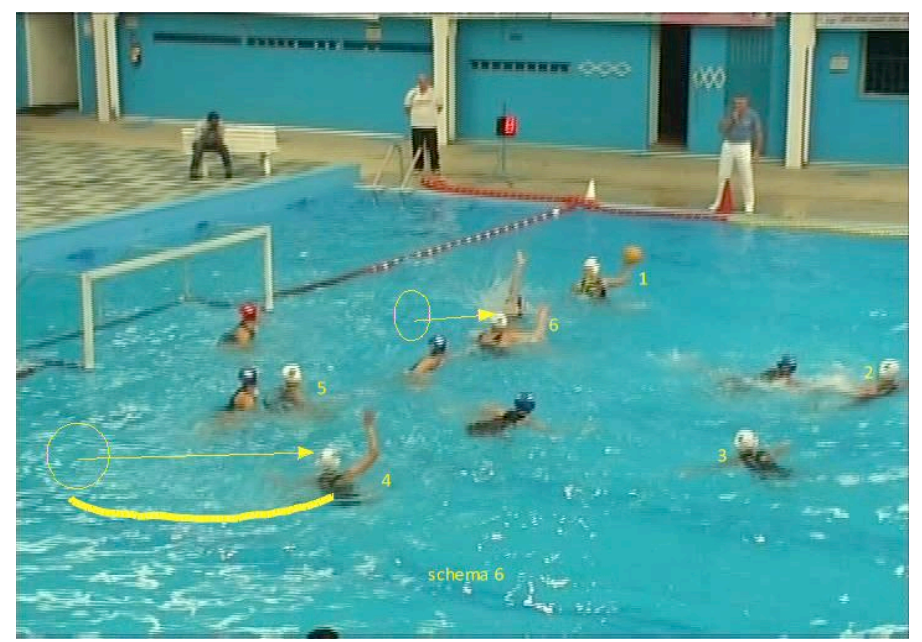

Figure 13. Pattern «schema6» Screenshot.

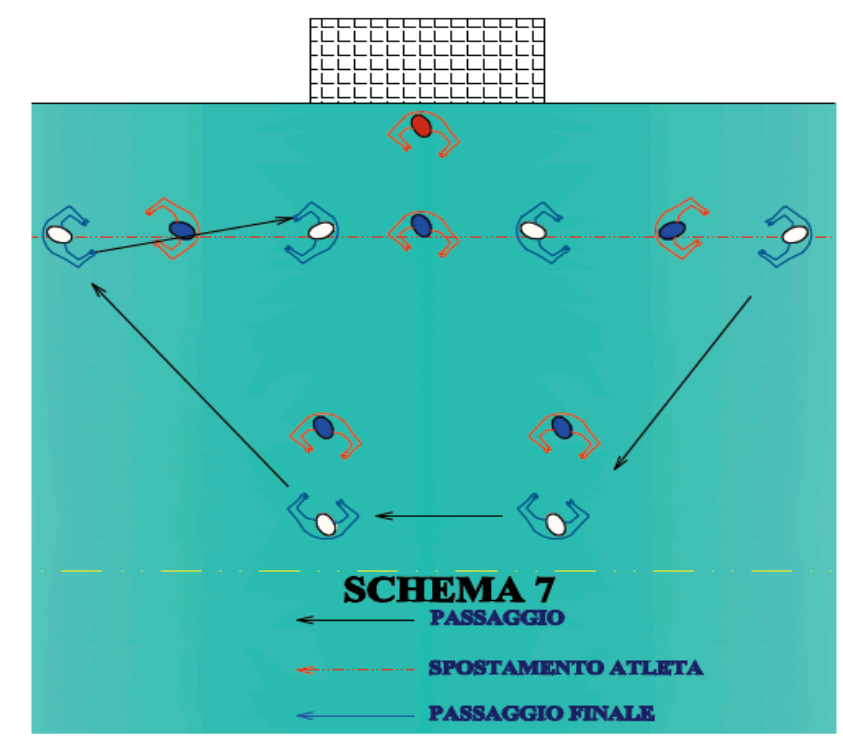

Figure14. Design of pattern named «schema7».

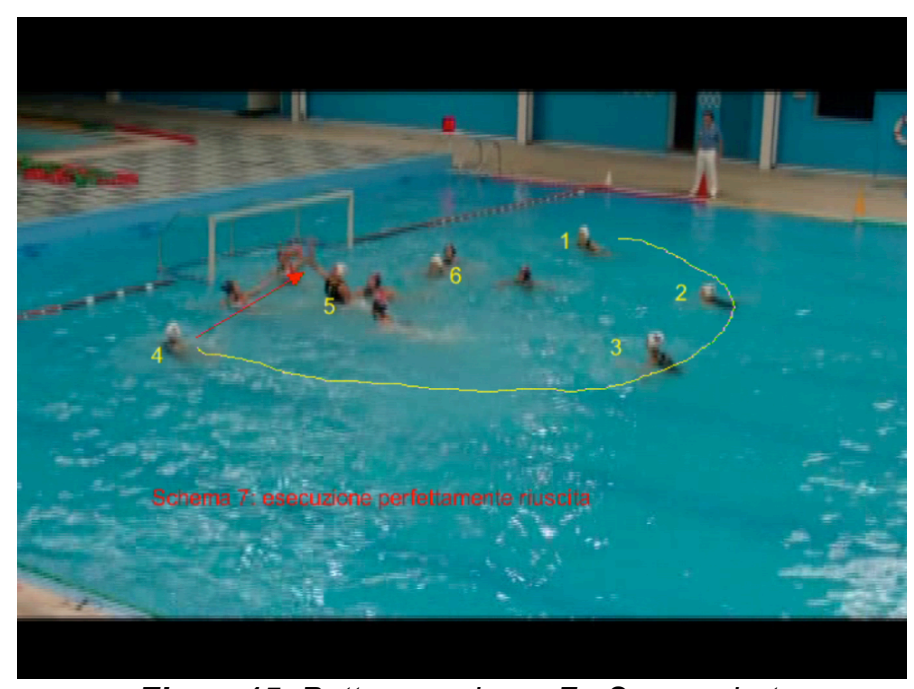

Figure15. Pattern «Schema7» Screenshot. 
Table 1. Patterns occurrence - 7 attack patterns on 73 events during 9 matches.

\begin{tabular}{rccc} 
Pattern & Occurrence & $\begin{array}{c}\text { Compliant } \\
\text { Occurrence }\end{array}$ & Goals \\
\hline Schema_1 & 15 & 10 & 6 \\
schema_2 & 6 & 3 & 3 \\
schema_3 & 8 & 3 & 2 \\
schema_4 & 8 & 4 & 3 \\
schema_7 & 25 & 21 & 13 \\
schema_1.2 & 7 & 5 & 1 \\
schema_6 & 4 & 4 & 2 \\
\hline
\end{tabular}

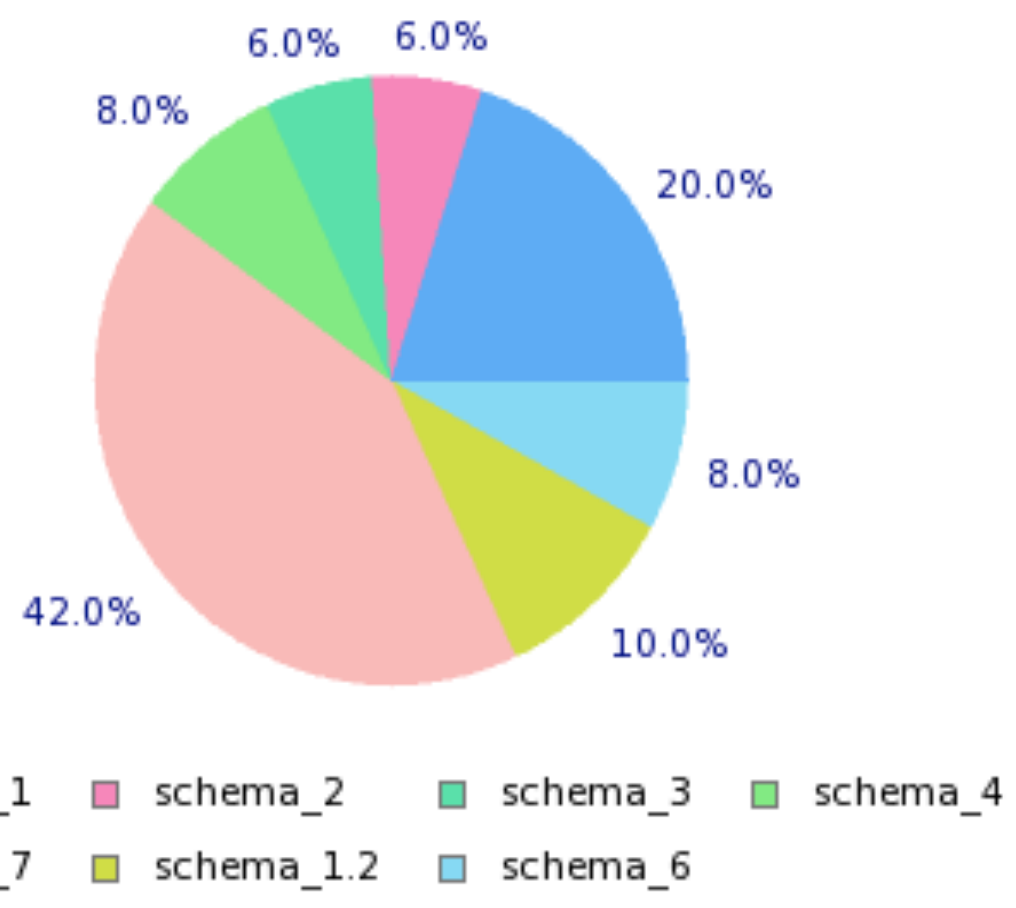

Figure 16. Well-performed patterns occurrence. 


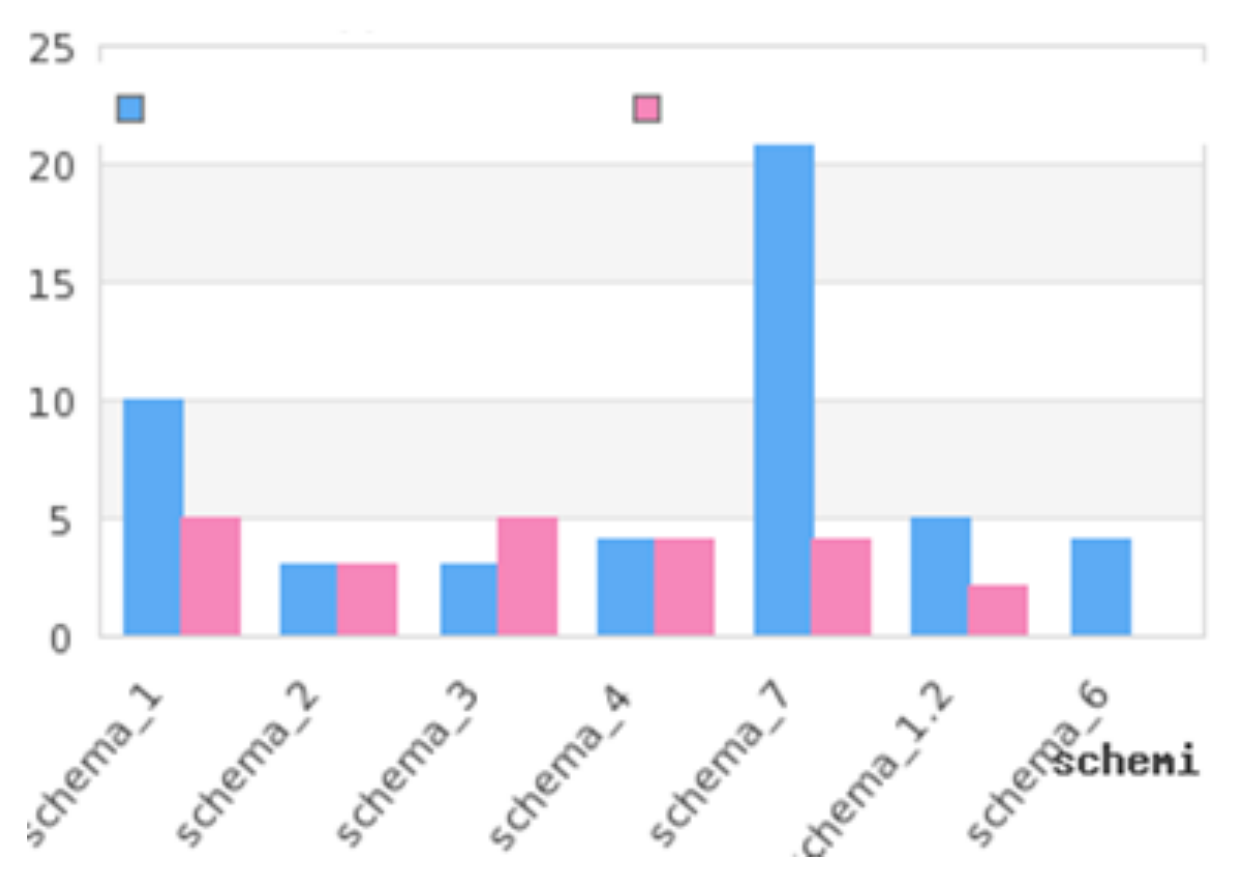

Figure 17. Pattern occurrence / well performed.

Table 2. Results: pattern Schema1.

\begin{tabular}{|c|c|c|c|}
\hline \multicolumn{4}{|c|}{ schema_1 } \\
\hline Match & $\begin{array}{c}\text { Total } \\
\text { occurrence }\end{array}$ & Well performed & goals \\
\hline volturno vs orizzonte ct & 2 & 1 & 0 \\
\hline volturno vs fiorentina fi & 0 & 0 & 0 \\
\hline volturno vs ortiga sr & 3 & 2 & 1 \\
\hline volturno vs firenze pn & 2 & 2 & 2 \\
\hline volturno vs padova & 1 & 0 & 0 \\
\hline volturno vs messina & 1 & 1 & 1 \\
\hline volturno vs imperia & 2 & 1 & 1 \\
\hline volturno vs pro recco & 2 & 2 & 0 \\
\hline volturno vs bologna & 2 & 1 & 1 \\
\hline
\end{tabular}


Table 3. Correlation (well performed patterns / Goals).

\begin{tabular}{ccc} 
Pattern & stderr & $\begin{array}{c}\text { correlation (well performed } \\
\text { patterns } / \\
\text { Goals ) }\end{array}$ \\
\hline schema_1 & 0.43678760300431 & 0.76332253361379 \\
schema_2 & 0 & 1 \\
schema_3 & 0.30860669992418 & 0.75592894601845 \\
schema_4 & 0.11624763874382 & 0.98810492932246 \\
schema_7 & 0.54916964736528 & 0.22360679774998 \\
schema_1.2 & 0.34684398780965 & 0.22941573387056 \\
schema_6 & 0.37796447300923 & 0.5976143046672 \\
\hline
\end{tabular}

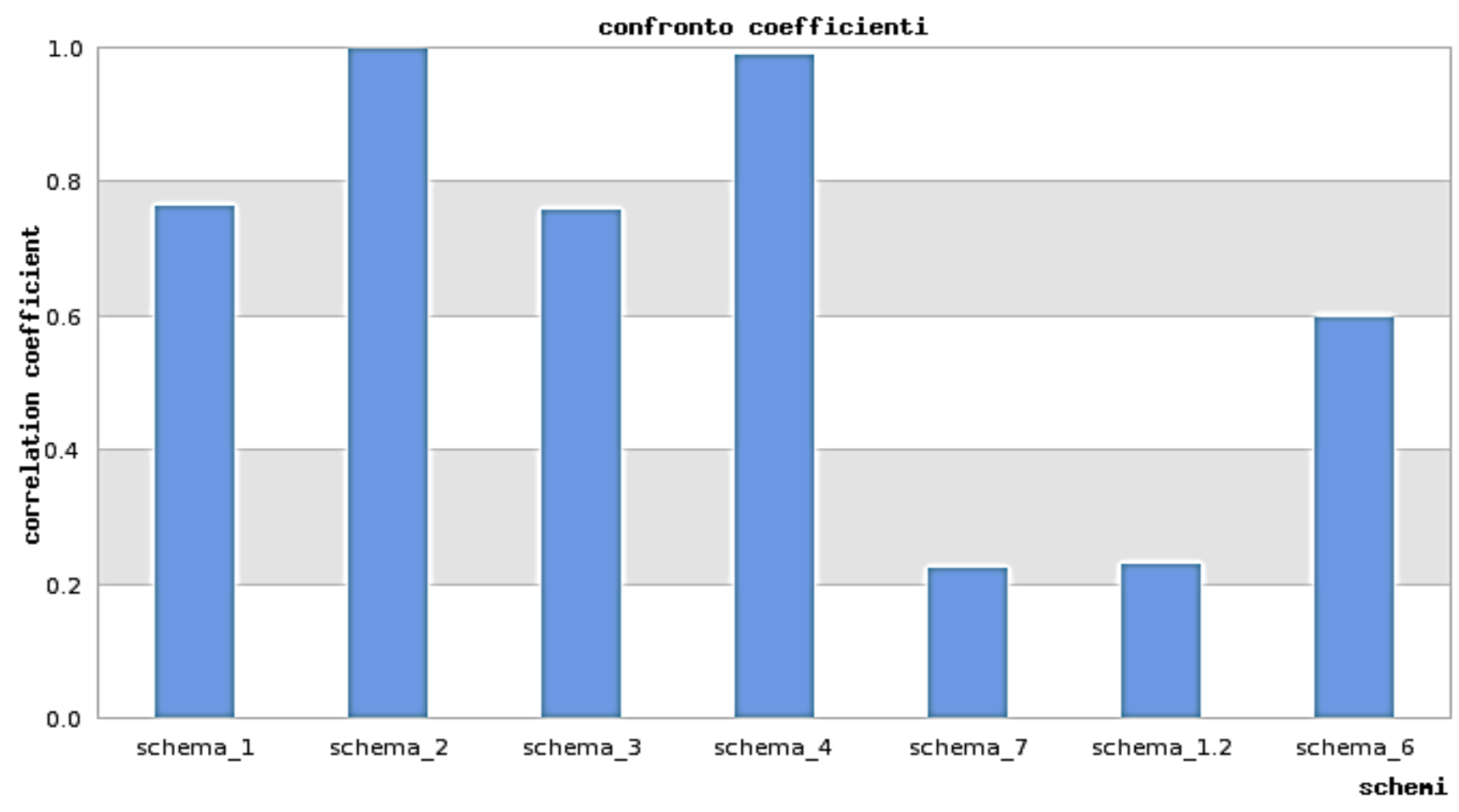

Figure 18. Confrontation between cofficients. 


\section{DISCUSSION}

The results showed a general efficacy of tactical patterns (when they are well performed), but showed significant differences within correlation coefficients of single patterns, knowing that "the correlation coefficient indicates magnitude or amount of a relationship and the direction of relationship" [Morrow, Jackson].

A more consistent data base is needed, in order to establish direct, evident and general relationship between so calculated coefficient and pattern efficacy, and the research team is conscious of internal validity of this kind of qualitative analysis, which can't extend, without adjustments, to other teams.

Although, analysis results represents a tool for the coach, in order to better train team in next season, which were an aim of action research, and showed a general trend on tactical pattern efficacy, which will be deeply investigated in future works.

\section{REFERENCES}

1. DI TORE PA, RAIOLA G. Exergames in motor skill learning. Journal of Physical Education and Sport. 2012; 12(3): 358-361.

2. HUGHES M. "Notational analysis - a mathematical perspective". International Journal of Performance Analysis in Sport. 2004; 4(2): 97-139.

3. HUGHES M. The essentials of performance analysis: an introduction. Taylor \& Francis. 2007.

4. HUGHES MD, FRANKS I. Notational Analysis of Sport: Systems for Better. Coaching and Performance in Sport. Routledge. 2008.

5. SCHMIDT R, WRISBERG C. Motor learning and Performance. Human Kinetics. 2008. 